\title{
Direct measurement of local pressures in the cadaveric human hip joint during simulated level walking
}

\author{
D ADAMS AND S A V SWANSON \\ From the Department of Mechanical Engineering, Imperial College, London
}

SUMMARY Eleven piezoelectric pressure transducers, each supporting an area of articula⿳亠丷厂巾 cartilage about $3 \mathrm{~mm}$ in diameter, were inserted through the bone of the acetabulum. Nin cadaveric hip joints, thus instrumented, were subjected to forces representing six instants in $\dot{\mathrm{i}}$ typical level walking cycle, including the highest and lowest force. Under the highest force, the maximum pressure measured ranged from 4.93 to $9.57 \mathrm{MN} \mathrm{m}^{-2}$. The transducer positions whic were subjected to the highest pressures were subjected at some other instant in the cycle t $\underline{\theta}$ pressures which were an order of magnitude lower, or to zero pressure.

Key words: articular cartilage, walking, nutrition, fibrillation.

Any discussion of the lubrication of synovial joints or the transmission of load through them involves a knowledge of the pressures exerted between the two layers of articular cartilage which constitute the bearing surfaces or assumptions about them.

To obtain an estimate of the average pressure in a given joint is not difficult. The forces transmitted through many of the major joints of the human skeleton in common activities are known with reasonable accuracy. ${ }^{12}$ The contact area in a cadaveric specimen in a chosen configuration and subjected to a chosen load can be measured. ${ }^{3}$ Thus average pressures can be calculated.

There is no reason to expect the pressure in a joint under load to be uniform over the articular surfaces, and estimates of the average pressure are merely first steps to knowing the detailed distribution of pressure.

Attempts ${ }^{4}$ to infer pressure distributions from observed variations in the density of subchondral bone rest on sweeping assumptions about the relationship between stress and bone density, and, whatever their validity, could not give variations in stress distributions during activities.

Day $e t a l .{ }^{6}$ found the average pressure on each of three or four zones of cartilage in the human

Accepted for publication 15 March 1985.

Correspondence to Professor S A V Swanson, Mechanical Engineering Department, Imperial College, London SW7 2BX. acetabulum by loading a hip joint to three tion body weight and measuring the deformation unieg load of one zone of cartilage as the other zones was successively removed. Seventeen hips were tested zonal pressures varied from zero to 3.4 times the average pressure, and the highest zonal pressure found were $4.5 \mathrm{MN} \mathrm{m}^{-2}$, on thin fibrocartilage at the zenith of certain acetabula.

Small pressure transducers have been incor porated in femoral head prostheses ${ }^{78}$ and in at acetabular prosthesis. ${ }^{9}$ The latter produced sur prisingly low pressures of up to $0.5 \mathrm{MN} \mathrm{m}^{-2}$ with $\frac{\bar{\alpha}}{\mathbf{0}}$ load of $2.96 \mathrm{kN}$; the former series have reporte local pressures of up to $6.8 \mathrm{MN} \mathrm{m}^{-2}$ and average pressures of 2-5 $\mathrm{MN} \mathrm{m}^{-2}$ under a load of $1.35 \mathrm{kN}$ Both these investigations suffer from the limitation which result from the use of a metallic surface is place of one of the two cartilage surfaces.

After preliminary results of the present investiga tion had been published ${ }^{10}$ Mizrahi et al. ${ }^{11}$ publishe results obtained with an essentially similar method? Transducers were inserted in the acetabulum, but they were larger (the hole for each transducer was apparently about $7.5 \mathrm{~mm}$ in diameter) and only fou were used in each specimen. Loads of up to 500 (less than a typical body weight) were applied if seven positions of the joint, but it does not appeat that the directions of loading were coordinated witt the joint attitudes so as to represent any specifie activity; and no precautions seem to have been 
taken to make the compliance of the transducer supports similar to that of the surrounding bone.

The object of the present work was to measure pressures in or adjacent to the articular cartilage of the cadaveric human hip, at representative instants in a typical walking cycle, using as many and as small pressure transducers as practicable.

\section{Materials and methods}

\section{HIP JOINTS}

Nine hip joints (acetabulum plus proximal quarter of femur) were used from cadavers ranging from 20 to 84 years old, in all of which the cause of death did not suggest abnormalities of cartilage or bone (see Table 1). All articular surfaces were brushed with Indian ink; all surfaces, both femoral and acetabular, showed fibrillation round the margins and spreading inwards to different extents, but none showed more than very slight Indian ink staining on the superior aspect of the femoral head or the central strip of the acetabular cartilage. Particular features of certain hips are mentioned in the discussion of results.

Table 1 Hip joints tested

\begin{tabular}{|c|c|c|c|c|c|c|}
\hline $\begin{array}{l}\text { Hip } \\
(N o)\end{array}$ & $\begin{array}{l}\text { Age } \\
\text { (years) }\end{array}$ & Sex & $\begin{array}{l}\text { Body } \\
\text { mass } \\
(k g)\end{array}$ & $\begin{array}{l}\text { Height } \\
(m)\end{array}$ & $\begin{array}{l}\text { Left } \\
\text { or } \\
\text { right }\end{array}$ & $\begin{array}{l}\text { Mean diam. of } \\
\text { femoral head } \\
(\mathrm{mm})\end{array}$ \\
\hline 1 & $?$ & F? & $57 \cdot 2 ?$ & $?$ & $\mathbf{L}$ & $44 \cdot 6$ \\
\hline 2 & 69 & $\mathbf{M}$ & $72 \cdot 1$ & $?$ & $\mathbf{R}$ & $52 \cdot 6$ \\
\hline 3 & 84 & $\mathbf{F}$ & $58 \cdot 0$ & $1 \cdot 55$ & $\mathbf{R}$ & $44 \cdot 8$ \\
\hline 4 & 20 & $\mathbf{F}$ & $46 \cdot 3$ & $?$ & $\mathbf{R}$ & 40.4 \\
\hline 5 & 68 & $\mathbf{M}$ & 88.9 & $1 \cdot 78$ & $\mathbf{L}$ & $50 \cdot 2$ \\
\hline 6 & 45 & $\mathbf{M}$ & $65 \cdot 3$ & $1 \cdot 73$ & $\mathbf{R}$ & $50 \cdot 9$ \\
\hline 7 & 57 & $\mathbf{M}$ & $66 \cdot 2$ & $1 \cdot 79$ & $\mathbf{R}$ & $55 \cdot 3$ \\
\hline 8 & 53 & $\mathbf{M}$ & $78 \cdot 0$ & 1.73 & $\mathbf{R}$ & $48 \cdot 6$ \\
\hline 9 & 61 & $\mathbf{F}$ & 58.9 & $1 \cdot 70$ & $\mathbf{L}$ & $46 \cdot 6$ \\
\hline
\end{tabular}

MEASUREMENT METHODS

Pressure transducers

Since the aim was to insert about 10 pressure transducers into each hip, it was decided to insert them through the subchondral bone as far as the bone-cartilage junction; it was thought better to leave the cartilage intact and accept a measurement of pressure at the bone-cartilage junction than to incur the errors associated with placing the transducers through holes made right through the thickness of the cartilage. To insert several transducers through the cancellous bone of the acetabulum caused a proportionately much smaller disruption than if the transducers had been placed in the femoral head.

A piezoelectric transducer was designed and made. The transducing element was a cylinder of lead zirconate-lead titanate, $3 \mathrm{~mm}$ in diameter and 5 $\mathrm{mm}$ in length. It was supported in a cylindrical stainless steel case with a flexible diaphragm at one end transmitting applied forces to the transducing element from an end piece $2 \mathrm{~mm}$ in diameter. At the other end of the case there was provision for mounting the transducer in cancellous bone and for attaching electrical leads, as shown in Fig. 1. The considerable precautions needed to exclude moisture and to preserve the correct electrical characteristics were developed as early models were tested.

\section{Recording apparatus}

Each pressure transducer was connected to an operational amplifier (Analog Devices type 311J) having an input impedance of greater than $10^{14} \Omega$ and a leakage current of $10^{-14} \mathrm{~A}$; the amplifier outputs were fed via $10 \mathrm{k} \Omega$ variable resistors to the galvanometers of a multichannel ultraviolet (UV) recorder.

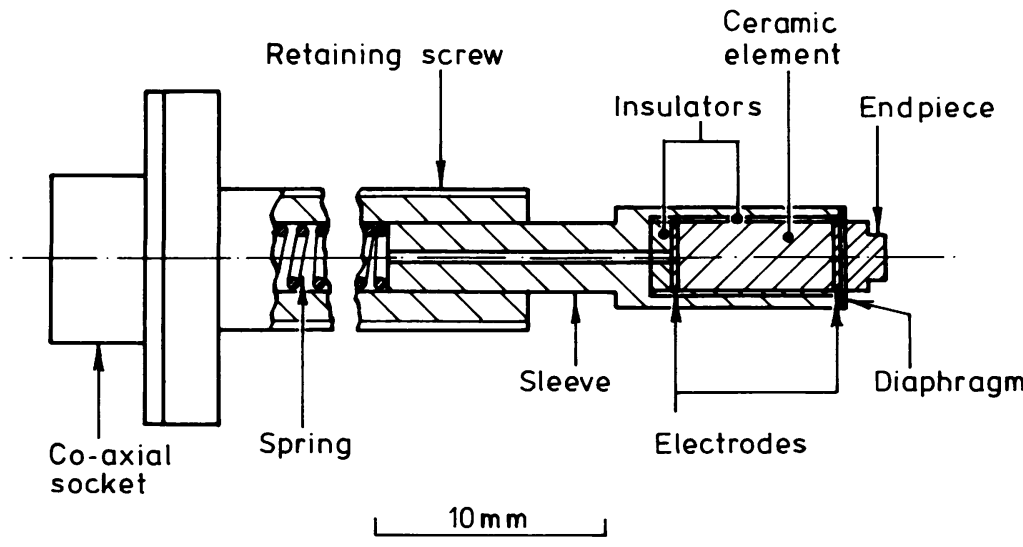

Fig. 1 Cross section of piezoelectric pressure transducer. 


\section{Calibration apparatus}

Each transducer was calibrated before insertion into bone by applying dead weights to its end piece; this required no special apparatus. Before and after each main test all the transducers were calibrated in situ by applying hydrostatic pressure through a hemispherical rubber capsule, by means of a pressure transducer connected to one channel of the UV recorder (the 11 transducers to be calibrated were connected to 11 other channels), a pump and release valve, and a Bourdon pressure gauge for easy visual monitoring.

On specimens 1,2 , and 3 a rubber capsule was used which was less flexible and more uneven in its outside shape than was desirable; these features were improved in the capsule used in later tests, and the calibrations in the first three specimens are more open to doubt than the others.

\section{Loading apparatus}

Each hip joint was loaded in the compression space of a materials testing machine (Hounsfield Tensometer type E); the load axis was always vertical, and fixtures allowed the femoral head and the acetabulum to be held in positions relative to this vertical axis which represented both the relative attitudes of the two components of the joint and the direction relative to them of the load axis for the selected instants in the walking cycle.

\section{Mounting pressure transducers in bone}

As shown in Fig. 1 each transducer was located coaxially in a hole drilled in a $6 \mathrm{~mm}$ bolt, with the sensitive end of the transducer protruding beyond the end of the screw and its other end resting on a helical compression spring inside the screw. The

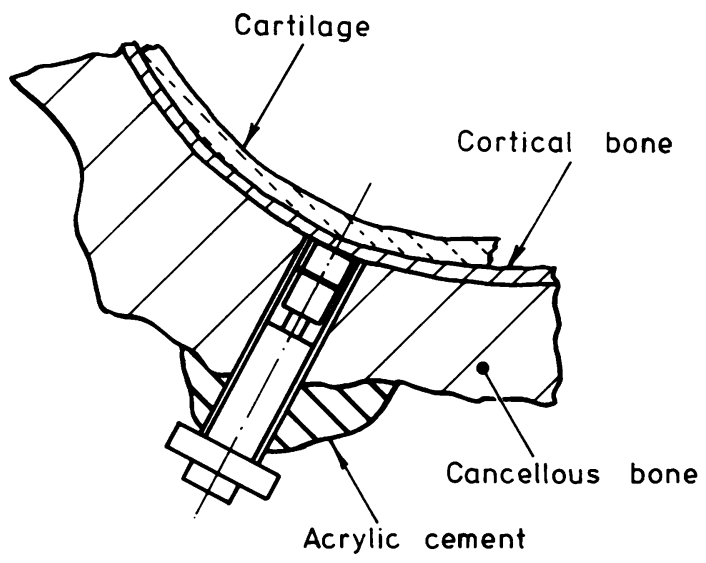

Fig. 2 Pressure transducer in position in the acetabulum.

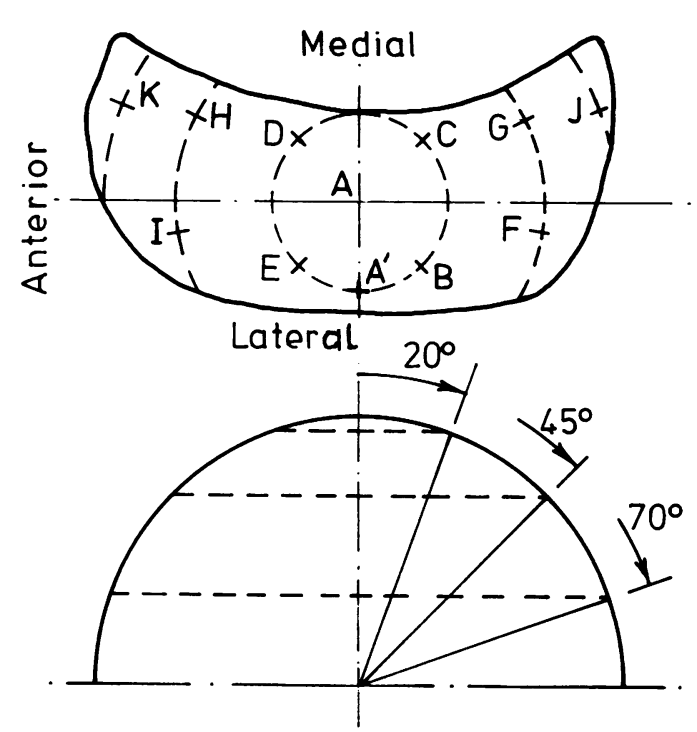

Fig. 3 Disposition of 11 pressure transducers over the articular surface of the acetabulum.

purpose of this spring was to reduce the otherw $8 \overrightarrow{\varepsilon_{0}}$ excessive stiffness of the all-metal transdueepr assembly to a value within the range given by tosts on cancellous bone of several acetabula.

In each intended transducer position a hole $6 \cdot 3$ 등 $\mathrm{mm}$ in diameter was drilled through the cancellousू bone as far as the cortex; a flat-ended cutter of the same diameter was then used to make a plane surface on the cortical bone, normal to the axis of the hole. An annulus of bone $2.75 \mathrm{~mm}$ in outen diameter and $2.0 \mathrm{~mm}$ inner diameter was ther removed through the full thickness of the corticat bone by a tool made for the purpose. Coaxial witho the hole, but remote from the cartilage and cortex acrylic resin was cast in the form of a female thread. to accept the bolt holding the transducer; this resing was cast so as to fit both the cancellous bone and the supporting fixture for the acetabulum. Fig. 2 shows the arrangement for one transducer. Just before the transducers were required for use each transducer in its supporting bolt was screwed into its hole in then acetabulum, and its axial position was adjusted untif the smallest detectable load was registered; it was then locked in that position with a locknut.

\section{Disposition of pressure transducers}

Eleven transducers were fixed in each acetabulum by the method just described, disposed as shown in ${ }^{?}$ Fig. 3. For test No 9, in which it was necessary to use the zenith of the acetabulum for a different measurement (see below), transducer position A was dis $-\Omega$ 
placed to $\mathrm{A}^{\prime}$. The positions shown are those for a right hip; a mirror image of this disposition was used for a left hip, so that positions B, C, F, G, and J were always posterior and positions $\mathrm{D}, \mathrm{E}, \mathrm{H}, \mathrm{I}$, and $\mathrm{K}$ were always anterior.

\section{Preparation of specimens}

The hip joints, which had not been embalmed, were stored at $-18^{\circ} \mathrm{C}$ until needed, when they were thawed to room temperature. All preparations for mounting the pressure transducers in the acetabula, and the bones in the testing machine, were completed the day before testing, so that calibrations and tests could be completed within one day. Overnight storage was at $-18^{\circ} \mathrm{C}$, and at all times when exposed to room temperature the bones were wrapped with tissues soaked in Ringer's solution to minimise drying of the tissues.

\section{Calibrations}

Each acetabulum with pressure transducers in place was pressurised three times up to $2.76 \mathrm{MN} \mathrm{m}^{-2}$ by the apparatus described above, with an interval of 15 min between successive applications. Full pressure was reached in about $7 \mathrm{~s}$ (range 3-16 s), a rate of loading similar to that in the main tests. After all other tests had been completed the calibration was repeated, three sets of readings usually being taken.

\section{Forces and attitudes for main tests}

From the work of Paul $^{1}$ a representative cycle of resultant force on the femoral head during level walking was selected, and within this cycle six instants (shown in Fig. 4) were selected to include the highest and lowest forces.

The direction of the resultant force relative to axes fixed in space was given by Paul in the form of three Cartesian components of force. The attitudes of the pelvis and proximal femur relative to axes

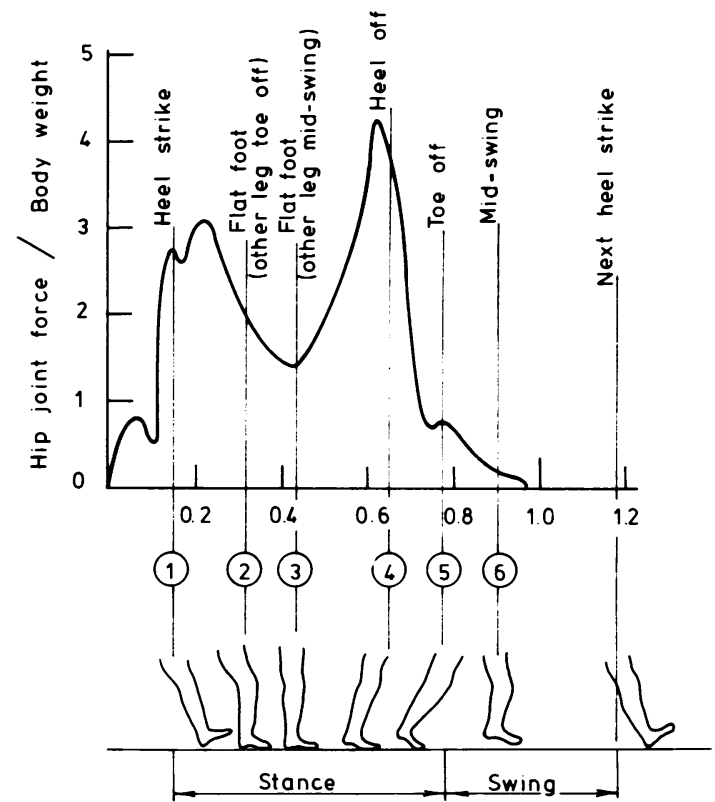

Fig. 4 Representative cyclic variation of resultant force on the femoral head during level walking (after Paul').

fixed in space were taken from Eberhardt ${ }^{12}$ and were combined with Paul's results to give a configuration (i.e., the attitudes of the pelvis and of the proximal femur in the testing machine, and the maximum load to be applied) representing each of the chosen six instants in the walking cycle. Paul's results were expressed as ratios of resultant force to body weight, and the relevant ratios were applied in turn to the body weights of the cadavers from which the specimens had come. The six configurations used are described numerically in Table 2 .

Table 2 Particulars of the six configurations in the walking cycle selected for study

\begin{tabular}{|c|c|c|c|c|c|c|c|c|c|c|c|}
\hline \multicolumn{2}{|c|}{ Configuration* } & \multicolumn{3}{|c|}{ Forcelbody weight ${ }^{+}$} & \multirow[t]{2}{*}{ Resultant } & \multicolumn{3}{|c|}{ Rotations of fermur (deg) } & \multicolumn{3}{|c|}{ Rotations of pelvis (deg) } \\
\hline & & $F_{x}$ & $F_{y}$ & $F_{z}$ & & $\theta_{v}$ & $\theta_{y}$ & $\theta_{z}$ & $\theta_{1}$ & $\theta_{y}$ & $\theta_{z}$ \\
\hline 1 & HS & 0.45 & 0.43 & $-2 \cdot 74$ & $2 \cdot 81$ & -1 & 34 & -4 & 0 & 0 & 5 \\
\hline 2 & $\mathrm{FF}(\mathrm{TO})$ & 0 & 0.77 & -1.93 & $2 \cdot 08$ & 0 & 15 & +8 & 2 & 0 & 7 \\
\hline 3 & FF(MS) & 0 & 0.52 & -1.53 & 1.62 & 0 & () & 0 & 0 & 0 & 0 \\
\hline 4 & $\mathrm{HO}$ & -0.77 & $1 \cdot 13$ & -3.94 & $4 \cdot 17$ & 3 & -12 & -5 & 2 & -2 & -5 \\
\hline 5 & TO & $-0 \cdot 18$ & 0 & $-0 \cdot 61$ & $0 \cdot 64$ & 7 & 5 & -13 & $-1 \cdot 5$ & -2 & -5 \\
\hline 6 & MS & 0.09 & 0 & -0.21 & $0 \cdot 23$ & 0 & 32 & -12 & 2 & 0 & -1 \\
\hline
\end{tabular}

HS=heel strike; $F F(T O)=$ flat foot (other leg toe off); $F F(M S)=$ flat foot (other leg mid-swing); $H O=$ heel off: $T O=t o c$ off; MS $=$ mid-swing

+ The components of force are those of the force on the femoral head. Coordinate directions: $x=$ horizontal. anterior: $y=h o r i z o n t a l$. lateral; $z=$ vertical, upwards.

${ }^{\ddagger}$ Rotations are positive according to the right-hand screw rule. 
662 Adams, Swanson

Table 3 Pressures measured in main tests (all pressures in $M N m^{-2}$ )

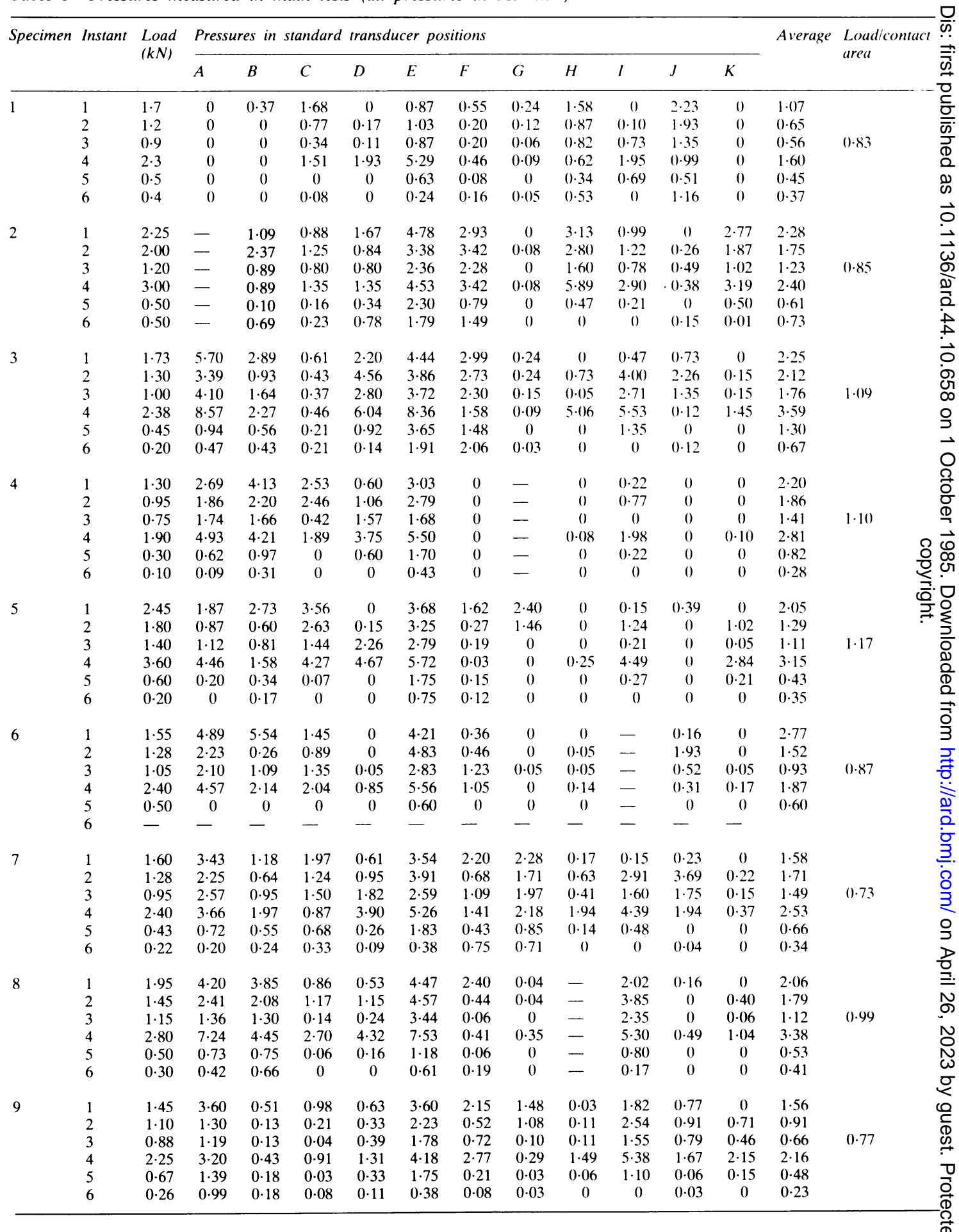




\section{Main tests}

Each specimen was tested first in the configuration corresponding to instant 3 in the walking cycle and then in the other five configurations. Three specimens were finally tested again in the configuration corresponding to instant 3 as a check on repeatability. Usually two or more rates of loading were used in each configuration, and various other check tests (see Appendix) were added to the basic sequence. Between each load application and the next the specimen was left under no load for at least 15 minutes.

The standard loading rate was that obtained with a crosshead speed of $20 \mathrm{~mm} \mathrm{~min}{ }^{-1}$, with which a force of three times body weight was reached in about $7 \mathrm{~s}$.

\section{Results}

The results of the controls and check tests are given in the Appendix. The results of the main tests are presented in Table 3 (where the average of each row is the average of the non-zero values), and the highest pressure measured in each specimen is shown in Table 4 . Table 3 shows also the load divided by the projected area of acetabular cartilage, which represents the greatest contact area theoretically available. For specimen No 7 the variations of the measured pressures during the simulated walking cycle are shown in Fig. 5.

\section{Discussion}

RELIABILITY OF RESULTS

No independent method of known accuracy exists with which even some of the results could be compared, and therefore reliance must be placed on repeatability and the reasonableness of the results when compared with other relevant information. As stated above the calibrations in specimens 1,2 , and 3 were believed to be less reliable than in later

Table 4 Highest pressure measured in each specimen, with appropriate margin of error

\begin{tabular}{llll}
\hline Specimen & $\begin{array}{l}\text { Pressure } \\
\left(M N m^{-2}\right)\end{array}$ & $\begin{array}{l}\text { Margin of error } \\
\left(M N m^{-2}\right.\end{array}$ & $\begin{array}{l}\text { Configuration and } \\
\text { transducer position }\end{array}$ \\
\hline 1 & $5 \cdot 29$ & \pm 1.43 & $4, \mathrm{E}$ \\
2 & 5.89 & \pm 3.08 & $4, \mathrm{H}$ \\
3 & 8.57 & \pm 1.18 & $4, \mathrm{~A}$ \\
4 & 5.50 & \pm 0.69 & $4, \mathrm{E}$ \\
5 & 5.72 & \pm 0.45 & $4, \mathrm{E}$ \\
6 & 5.56 & & $4, \mathrm{E}$ \\
7 & 5.26 & \pm 0.20 & $4, \mathrm{E}$ \\
8 & 7.53 & \pm 0.67 & $4, \mathrm{E}$ \\
9 & 5.38 & \pm 0.27 & $4, \mathrm{I}$ \\
\hline
\end{tabular}

specimens, and this is confirmed by the $95 \%$ confidence limits shown in Tables A2 and A3. When only the highest measured pressures are considered. Table 4 shows that in the later tests the margin of error was about $\pm 10 \%$. As mentioned in the Appendix the greatest error probably resulted primarily from partial dehydration of the joint during testing, which would cause changes to the dimensions and perhaps the mechanical properties of the cartilage.

Another source of error of a different kind is a possible mismatch of the compliance of each trans-
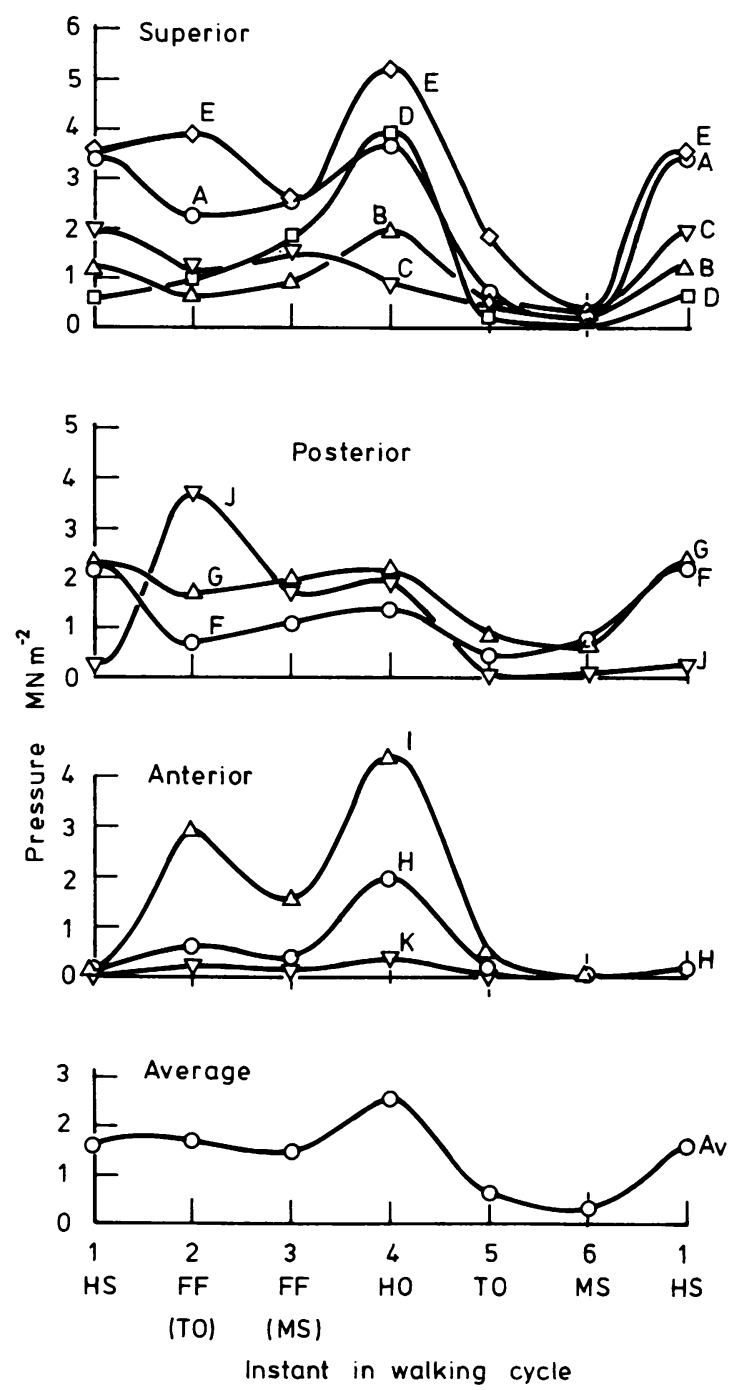

Fig. 5 Variations of measured pressures in specimen 7 during simulated walking cycle. 
ducer mounting to that of the surrounding cancellous bone. Within the limitations of the present method the best that can be done is to hope that the mismatch is not systematic and that with a reasonable number of measurements the errors will not obscure the pattern of results.

VARIATION OF PRESSURES DURING SIMULATED WALKING CYCLE

The pressure transducers occupied a total area equivalent to about $5 \%$ of the area of the acetabulum, and statements about the distribution of pressure must therefore be made with caution.

The most obvious feature of the results is that the pressures varied both over the articular surface and during the simulated walking cycle. The highest pressure ranged from 5.26 to $8.57 \mathrm{MN} \mathrm{m}^{-2}$ (Table 4 ), and from Table 3 it can be seen that these maxima were appreciably higher than the average of all pressures measured in the configuration concerned; the ratio ranged from 1.82 to 3.3 . The average of 11 pressures measured under 11 small areas is not necessarily the average pressure on the whole area in contact; and the measured maxima must be lower bounds on the true maxima, because some of the $95 \%$ of the total area not instrumented may well have been subjected to higher pressures. All these maxima were measured in configuration 4 , i.e., the instant of heel off, with a resultant hip force of $4 \cdot 17$ times the body weight. A comparison of Figs 4 and 5 shows the general level of pressures, and the maxima, to be broadly proportional to the magni- $\frac{2}{3}$ tude of the resultant force on the hip joint.

\section{RELATIONSHIP OF PRESSURES TO}

DEGENERATIVE STATE OF CARTILAGE

As mentioned above all nine specimens showed some fibrillation around the articular margins of both the acetabulum and the femoral head; Nos 2, 3,,$\overline{\mathrm{Q}}$ 5,7 , and 9 had light fibrillation posteriorly on the femoral articular surface and Nos 6 and 7 anteriorly, while Nos 6 and 7 had some fibrillation laterally on $\vec{e}$ the acetabular articular surface, and Nos 5 and $9=$ showed a small zone at the zenith which retained Indian ink. Comparison of these observations withe the measured pressures suggests no correlations.

CYCLIC STRESSING AND ITS SIGNIFICANCEÖ The only pressures which were nearly constanto during the simulated walking cycle were those thato were an order of magnitude smaller than the? average; the points subjected to the highest pressures(at heel strike and heel off) were, in general $O$ subjected to pressures an order of magnitude loweró (if not actually zero) at other parts of the cycle. Thed exception to this generalisation is position $\mathrm{E}$ in specimens 2 and 3, where the lowest pressures wegeoo respectively 0.374 and 0.228 times the maximt pressures. These results support and should perfisito the refinement of earlier statements ${ }^{13}$ that thes nutrition of adult articular cartilage is achievedo partly by the pumping of nutrients in from theo articular surface.
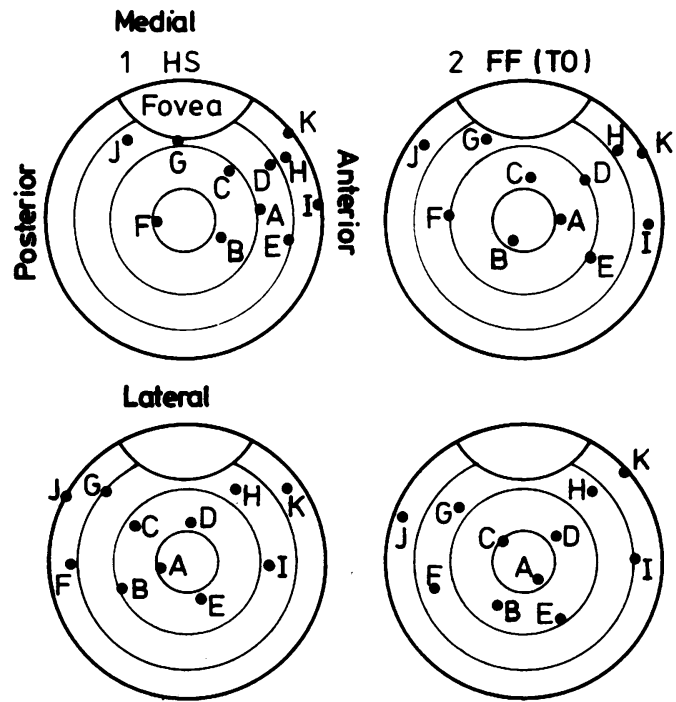

$4 \mathrm{HO}$





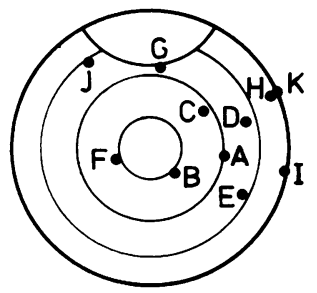

6 MS
Fig. 6 Pressure transducer positions transferred to the femoral head, viewed from vertically aboven the centre of the head. 
These results provide a closer estimate than hitherto available of the stress ranges to which cartilage is subjected in life, and hence of the stress ranges which should be used in laboratory fatigue testing. Most postmortem observations of the state of cartilage in the hip joint have been made on the femoral head; the transducer positions on the acetabulum can be transferred to the femoral head in each of the six configurations tested, and the results are shown in Fig. 6. This shows that transducer positions $\mathrm{A}$ and $\mathrm{E}$, which most frequently showed the highest pressures, were over the zenith of the femoral head in configuration 4 , in which the highest pressures usually occurred. This observation can be compared with that of Byers et al. ${ }^{14}$ who found that the incidence of femoral head fibrillation seen in a postmortem examination was highest at and around the zenith of the femoral head.

This investigation was started by Dr G E Kempson, who left Imperial College before the techniques had been fully developed. One of the authors (DA) was supported by a Research Studentship from the Medical Rescarch Council. and this paper is based on a thesis for which he was awarded the degree of Doctor of Philosophy in the University of London.

\section{Appendix: Controls and check tests}

Procedures and results

(a) Dead-weight calibration of each pressure transducer before insertion in bone: all transducers gave responses linear to within $2 \%$ over the range 0 to $15 \mathrm{MN} \mathrm{m}^{-2}$.

(b) Three calibrations by hydrostatic pressure, of all pressurc transducers in situ before each set of main tests and three calibrations (when possible) after each set of main tests (about 200 graphs of transducer response against hydrostatic pressure). The coefficient of determination was used to indicate the linearity of response. and 181 calibrations gave values greater than 0.95; three transducers (which were seen to behave erratically during the tests) gave values less than 0.90 . The repeatability of the calibration of any one transducer in situ was represented by the difference between the gradients of the calibration lines obtained before and after the main tests. expressed as a percentage of the average of the two gradients. Eight of 96 pairs of gradients differed by more than $20 \%$ of their respective means, 26 by between 5 and $10 \%$, and 46 by up to $5 \%$.

(c) Repetition of main test in configuration 3. after tests in all other configurations, on specimens 4,5 , and 9 . The range of pressure difference was from 0 to $1.28 \mathrm{MN} \mathrm{m}^{-2}$, with an average of $0.21 \mathrm{MN} \mathrm{m}^{-2}$, half of the differences being less than $0 \cdot 1 \mathrm{MN} \mathrm{m}^{-2}$. The pressure differences were not correlated with the pressures indicated by the respective transducers. and the readings obtained in the second test were not consistently higher or lower than those obtained in the first test.

(d) Repetition of test at standard loading rate without disturbing the apparatus in each of configurations 1 to 4 inclusive with all nine specimens. The greatest pressure difference was $0.58 \mathrm{MN}$ $\mathrm{m}^{-2}$ (the transducer in position $\mathrm{J}$ on specimen 6 in configuration 2); the average of all the differences was $0.086 \mathrm{MN} \mathrm{m}^{-2}$ and the root mean square value $0 \cdot 128 \mathrm{MN} \mathrm{m}^{-2}$; and the pressure differences were not significantly correlated with the pressures being measured.

(c) Repetition of certain tests at loading rates twice or half the standard rate. Doubling the loading rate produced higher indicated pressures: the difference ranged from $0.67 \mathrm{MN} \mathrm{m}^{-2}$ $(12 \%$ of the indicated pressure at the standard rate) to -0.12 $\mathrm{MN} \mathrm{m} \mathrm{m}^{-2}(100 \%$ of the smallest pressure indicated in the test concerned), with an average difference of $0.187 \mathrm{MN} \mathrm{m}^{-2}$. Halving the loading rate produced lower indicated pressures than at the standard rate: the differences were similar to those obtained by doubling the loading rate.

(f) Repetition of tests on specimens 4.5.8, and 9 in configuration 4 with the proximal femur rotated in the horizontal plane first $15 \mathrm{deg}$ internally and secondly 15 deg externally from its correct attitude. The greatest pressure difference in the four tests ranged from 1.34 to $1.75 \mathrm{MN} \mathrm{m}^{-2}$ : the average pressure difference was considerably less than this. The general shape of the pressure distribution was not changed by the rotations. and in general the changes resulting from internal rotations were in the opposite sense to those resulting from external rotation. The value of $15 \mathrm{deg}$ was considerably greater than the $\pm 2 \mathrm{deg}$ estimated error during the main tests.

(g) Repetition of tests on specimen 3 in configurations 3 and 4 after 10 weeks with all pressure transducers moved to different positions. In configuration 3 the pressure differences ranged from -1.26 to $1.47 \mathrm{MN} \mathrm{m}^{-2}$, with an average of $0.52 \mathrm{MN} \mathrm{m}^{-2}$ : in configuration 4 from -1.38 to 3.44 , with an average of 1.18 MN $\mathrm{m}^{-2}$. In both configurations the greatest difference between the two tests occurred at position $\mathrm{E}$ : in the second test the transducer in position I was defective and gave no response.

(h) Simultancous performance of the present method and that of Day et al. ${ }^{\circ}$ on specimen 9 in configuration 3 . For this test transducer position $\mathrm{A}$ had to be moved to $\mathrm{A}^{\prime}$ (Fig. 3). The positions of the transducers were such that pressures could not be measured in each of the four regions used by Day et al. but only for the inner two combined and the outer two combined. The results are shown in Table A1. Direct comparison of the results obtained by the two methods is hardly possible. because while one measures the average pressure on each of four regions of cartilage the other measures the pressures on each of 11 much smaller areas, and the average of any collection of these 'point' pressures is not necessarily the true average pressure on the region containing the transducers concerned.

Table Al Results of the present method and the method of Day et al."

\begin{tabular}{|c|c|c|c|}
\hline \multicolumn{2}{|c|}{ Method of Day et al. } & \multicolumn{2}{|c|}{ Present method } \\
\hline Zone & $\begin{array}{l}\text { Average pressure } \\
\left(M N \mathrm{~m}^{-2}\right)\end{array}$ & Position & $\begin{array}{l}\text { Pressure } \\
\left(M N \mathrm{~m}^{-2}\right)\end{array}$ \\
\hline A & 0.27 & $\begin{array}{l}\mathrm{A}^{\prime} \\
\mathrm{B}\end{array}$ & $\begin{array}{l}2 \cdot 83 \\
3 \cdot 66\end{array}$ \\
\hline B & $2 \cdot 61$ & $\begin{array}{l}C \\
D \\
E\end{array}$ & $\begin{array}{l}1.26 \\
0.85 \\
0.46\end{array}$ \\
\hline$A+B$ & $1 \cdot 82$ & Average & $1 \cdot 81$ \\
\hline $\mathrm{C}$ & 0.91 & $\begin{array}{l}F \\
G\end{array}$ & $\begin{array}{l}3.22 \\
0.44\end{array}$ \\
\hline$C+D$ & 1.09 & $\begin{array}{l}\mathrm{H} \\
\mathrm{I} \\
\mathrm{J} \\
\mathrm{K} \\
\text { Average }\end{array}$ & $\begin{array}{l}0.65 \\
2.50 \\
0.85 \\
1.47 \\
1.52\end{array}$ \\
\hline$A+B+C+D$ & 1.51 & $\begin{array}{l}\text { Average of } \\
\text { all } 11 \\
\text { positions }\end{array}$ & $1 \cdot 65$ \\
\hline
\end{tabular}


Table A2 Margin of error ( $\pm 95 \%$ confidence limits $\left.M N \mathrm{~m}^{-2}\right)$ due to calibration procedures averaged over all six $\cong$ configurations for each transducer position

\begin{tabular}{|c|c|c|c|c|c|c|c|c|c|c|c|c|}
\hline \multirow[t]{2}{*}{ Specimen } & \multicolumn{11}{|c|}{ Standard transducer positions } & \multirow[t]{2}{*}{ Average } \\
\hline & $A$ & $B$ & $C^{\prime}$ & $D$ & $E$ & $F$ & $G$ & $H$ & $I$ & $J$ & $K$ & \\
\hline 1 & 0 & 0.753 & $1 \cdot 15$ & 0.423 & 0.785 & $0 \cdot 608$ & 0.525 & $(0.448$ & $(0.290$ & $(0.498$ & $(0.570$ & 0.605 \\
\hline 2 & & 0.655 & 0.157 & 0.700 & 0.467 & 0.778 & $0 \cdot 653$ & 1.527 & 0.235 & $0 \cdot 360$ & 0.447 & 0.598 \\
\hline 3 & 0.682 & 0.183 & $0 \cdot 300$ & 0.697 & 0.278 & 1.792 & 0.765 & 0.603 & 0.640 & $(0.712$ & 0.663 & 0.605 \\
\hline 4 & 0.582 & 0.648 & 0.313 & 0.193 & 0.782 & $(0.250$ & - & 0.412 & 0.398 & $(0.270$ & 0.330 & 0.418 \\
\hline 6 & \multicolumn{12}{|c|}{ No post-test calibrations } \\
\hline 7 & 0.197 & 0.465 & - & 0.112 & $0 \cdot 173$ & 0.430 & $0 \cdot 613$ & 0.257 & 0.368 & 0.272 & 0.360 & 0.325 \\
\hline 8 & 0.367 & 0.392 & 0.418 & 0.135 & $0 \cdot 398$ & 0.173 & $0 \cdot 312$ & - & $0 \cdot 360$ & $(0 \cdot 180$ & 0.133 & (1).287 \\
\hline 9 & $0 \cdot 163$ & $0 \cdot 142$ & $(0.215$ & 0.302 & $1 \cdot 205$ & 0.168 & 0.292 & $0 \cdot 183$ & $(0.228$ & 0.282 & 0.135 & $(0 \cdot 3(0) 1$ \\
\hline
\end{tabular}

Table A3 Largest and second largest margins of error ( $\pm 95 \%$ confidence limits $M N \mathrm{~m}^{2}$ ) due to calibration procedures calculated for each specimen

\begin{tabular}{|c|c|c|}
\hline Specimen & $\begin{array}{l}\text { Margin of error } \\
\left( \pm M N \mathrm{~m}^{-2}\right)\end{array}$ & $\begin{array}{l}\text { Configuration and } \\
\text { transducer position }\end{array}$ \\
\hline \multirow[t]{2}{*}{1} & $1 \cdot 43$ & 1. $C: 4, E$ \\
\hline & $1 \cdot 37$ & 4. $C$ \\
\hline \multirow[t]{2}{*}{2} & $3 \cdot(08$ & 4. $\mathrm{H}$ \\
\hline & $1 \cdot 88$ & 1, $\mathrm{H}$ \\
\hline \multirow[t]{2}{*}{3} & $2 \cdot 24$ & 1. $\mathrm{F}$ \\
\hline & $2 \cdot 10$ & 2. F \\
\hline \multirow[t]{2}{*}{4} & $1 \cdot 45$ & 4. E \\
\hline & $1 \cdot() 2$ & 4. B \\
\hline \multirow[t]{2}{*}{5} & 0.54 & 1. $\mathrm{J}$ \\
\hline & 0.53 & 4. D; 2-6, J \\
\hline \multirow[t]{2}{*}{7} & $(0 \cdot 69$ & 1. $\mathrm{G}$ \\
\hline & $0 \cdot 67$ & 4. G \\
\hline \multirow[t]{2}{*}{8} & 0.67 & 4. $\mathrm{E}$ \\
\hline & 0.58 & 4. I \\
\hline \multirow[t]{2}{*}{9} & $1 \cdot 74$ & 4. $E$ \\
\hline & 1.58 & 1. $\mathrm{E}$ \\
\hline
\end{tabular}

This being so, all that can be said is that the results of the two methods seem to be compatible.

(j) Comparison of average pressures. In Table 3 the notional average pressure obtained by dividing the load at instant 3 by the projected area of acetabular cartilage is poorly correlated with the average of the measured pressures, as would be expected from the very different origins of the two sets of figures; but they differ at most by a ratio of $2: 1$.

(k) Comparison of integrated measured pressures with applied loads. Because the transducers sampled only about $5 \%$ of the theoretical contact area. the assignation of an area of cartilage to each transducer in order to derive 11 forces which can be integrated is largely guesswork. When this was done for specimens 7 and 9 at instant 4 the resultant load thus derived was about twice the load applied in the test.

\section{Discussion}

Consideration of all the results summarised above indicates that the largest single source of error was the variation in calibrations. The differences between the calibrations performed before and after the main tests (and any possible variation in transducer responses during the main tests) could have resulted from partial dehydration of the cartilage, movement of the transducers in their mountings, penetration of water into the transducers, or other causes. Practical experience suggests that partial dehydration is the most probable cause but whatever the cause the effect was such as to make the other effects investigated insignificant in comparison.

Only the errors resulting from the calibration procedure wer $\overrightarrow{0}$ considered, and $95 \%$ confidence limits were calculated for ever combination of specimen, configuration, and transducer position and are shown in summary in Tables $\mathrm{A} 2$ and $\mathrm{A} 3$. The margin 06 error applicable to the highest pressure measured in each specime? is shown in Table 4

\section{References}

1 Paul J P. Forces transmitted by joints in the human body. Pro Inst Mech Engrs 1967: 181: 8-15.

2 Morrison J B. Biomechanics of the knee joint in relationter normal walking. J Biomech 1970; 3: 51-61.

3 Greenwald A S. Bullough P G. O Connor J J. Weight be areas in the human hip joint. J Bone Joint Surg 1972: 157-63.

4 Wiggins K L, Malkin S. Bearing pressure distribution in bone joints. Wear 1972: 19: 53-60).

5 Oberlander W. Die Beanspruchung des menschlichen Hüfto gelenks. V. Dic Verteilung der Knochendichte im Acetabulum $Z$ Anat Entwick-Gesch 1973; 140: 367-84.

6 Day W H. Swanson S A V. Freeman M A R. Contact pressure in the loaded human cadaver hip. J Bone Joint Surg 1975: 57Bב

7 Carlson C E. Mann R W. Harris W H. A look at the prosthesis cartilage interface: design of a hip prosthesis containing pressure transducers. J Biomed Mater Res 1974; 8: 261-9.

8 Rushfeldt P D, Carlson C E. Mann R W. Harris W H. Scholle J M. Load distribution across human acetabular cartilage: ir vitro studies using an instrumented femoral head prosthesis. Bone Joint Surge 1975; 57A: 565.

9 Rumelhardt C. Tahnan Z. Banaud J. Comtet J J. Pressure measurement in a hip joint simulator. In: Wright $V$. Dowson $D$. eds. Evaluation of artificial joints. London: Biological Engineer ing Society. 1977: 51-67.

10 Adams D. Kempson G E. Swanson S A V. Direct measurement of local pressures in the cadaveric human hip joint. Med Bio Eng Comput 1978; 16: 113-5.

11 Mizrahi J, Solomon L. Kaufman B, Duggan T O’D. An experimental method for investigating load distribution in th cadaveric human hip. J Bone Joint Surg 1981; 63B: 610-3. N 12 Eberhardt H D, ed. Fundamental studies of human locomotion and other information relating to design of artificial limbs University of California. 1947.

13 Maroudas A, Bullough P G. Swanson S A V, Freeman M A R The permeability of articular cartilage. J Bone Joint Surg 1968@ 50B: $166-77$

14 Byers P D. Contepomi C A. Farkas T A. A post-mortem stud of the hip joint. including the prevalence of the features of the right side. Ann Rheum Dis 1970; 29: 15-31. 